\title{
Selective Chloride-Mediated Neat Ethanol Oxidation to 1,1-Diethoxyethane via an Electrochemically Generated Ethyl Hypochlorite Intermediate
}

\author{
Siqi Li and Bart M. Bartlett* \\ Department of Chemistry, University of Michigan, 930 N. University Avenue, Ann Arbor, MI \\ 48109 United States
}

Table of Contents

\begin{tabular}{|c|c|}
\hline Experimental Section & S2 \\
\hline $\begin{array}{l}\text { Figure S1. CV traces in aqueous solutions containing acid electrolytes at a scan rate } \\
\text { of } 100 \mathrm{mV} / \mathrm{s} \text {. Working electrode: glassy carbon disk; reference electrode: } \mathrm{Ag} / \mathrm{AgCl} \text {. }\end{array}$ & S4 \\
\hline $\begin{array}{l}\text { Figure S2. General }{ }^{1} \mathrm{H}-\mathrm{NMR} \text { spectrum of the reaction mixture after CPC experiments } \\
\text { with peak identification. }\end{array}$ & S4 \\
\hline Figure S3. GC-MS trace of the post CPC aliquot. & S5 \\
\hline $\begin{array}{l}\text { Figure S4. FT-IR spectrum for aliquot post CPC experiment. The absorption value } \\
\text { was normalized. The only visible difference was the build-up of water (O-H stretch } \\
\text { at } \sim 3360 \mathrm{~nm} \text {, H-O-H scissors at } \sim 1630 \mathrm{~nm} \text { ). }\end{array}$ & S5 \\
\hline $\begin{array}{l}\text { Figure S5. Extended-range UV-vis spectrum of a diluted aliquot after the } 1 \mathrm{~h} \text { CPC } \\
\text { experiment. The EtOCl signature peak remains as the only notable absorption feature } \\
\text { throughout the UV-vis range. }\end{array}$ & S6 \\
\hline $\begin{array}{l}\text { Figure S6. Long-time CPC experiment for measuring chloride recovery. CPC } \\
\text { potential: }+1.61 \mathrm{~V} \text { vs. } \mathrm{Fc}^{+/ 0} \text {. Black: } \mathrm{CPC} i-t \text { curve. Red: Charge passed } q-t \text { from } \\
\text { integrating the } i-t \text { curve. In total, } 96.77 \mathrm{C} \text { of charge passed, which would correspond } \\
\text { to } 50.1 \% \text { of chloride being consumed ( } 100.3 \mathrm{mM} \text { chloride consumption out of } 200 \\
\mathrm{mM} \text { if chloride reacted stoichiometrically. }\end{array}$ & S6 \\
\hline $\begin{array}{l}\text { Figure S7. Replicates of EtOCl degradation kinetics presented in Figure } 3 \text {. The } \\
\text { concentrations were determined by a combination of UV-vis spectroscopy and a } \\
\text { titration experiment. }\end{array}$ & S7 \\
\hline $\begin{array}{l}\text { Figure S8. Tafel slopes for varying concentration of chloride electrolyte in ethanol } \\
\text { solution. }\end{array}$ & S7 \\
\hline
\end{tabular}




\section{Experimental Section}

\section{Materials and Chemicals}

Tetrabutylammonium chloride $\left(\mathrm{Bu}_{4} \mathrm{NCl}, \geq 97.0 \%\right.$, Sigma-aldrich, recrystallized $)$. Tetrabutylammonium trifluoromethanesulfonate $\left(\mathrm{Bu}_{4} \mathrm{NOTf},>98.0 \%\right.$, TCI), sodium chloride (certified ACS, Fisher), sodium sulfate (99\%, Alfa Aesar), silver nitrate (99.9+\%, Alfa Aesar), ammonium iodide (>99\%, Sigma), L-ascorbic acid (certified ACS, VWR), ferrocene (98\%, Sigma-aldrich), calcium hypochlorite (Alfa Aesar), deuterated chloroform (Cambridge Isotope Laboratories), ethanol (200 proof, Fisher), acetic acid (glacier, Fisher) and hydrochlorous acid (concentrated, Fisher) were used as received unless specifically mentioned.

\section{Electrochemical Reactions Conditions}

All electrochemical measurements were carried out on a $\mathrm{CHI} 1000 \mathrm{C}$ electrochemical workstation ( $\mathrm{CH}$ Instruments) if not specifically stated. A glassy carbon disk electrode (3mm diameter, $\mathrm{CH}$ Instruments) was used as working electrode throughout the study. After each electrochemical measurement, the working electrode was polished by 0.3 -micron alumina and then rinsed with 200 proof ethanol, then dried with $\mathrm{N}_{2}$. A silver wire electrode soaked in a vessel containing the same solution as the bulk solution but separated by a glass frit was used as reference electrode. All electrochemical reactions were conducted in a glass 2-compartment cell with a glass frit as a separator (illustrated below). During CPC experiments, the cell was sealed to reduce the evaporation of ethanol and other volatile organic compounds. To calibrate the reference electrode to ferrocene redox couple, a $100 \mathrm{mM}$ ferrocene stock ethanol solution was prepared and added to the working solution, yielding a $10 \mathrm{mM}$ total concentration of ferrocene in the working solution. All electrolytes for quantification are prepared in volumetric flasks to certify the concentration. Tafel analysis was carried out on a CHI760C electrochemical workstation using the same electrodes (working: glassy carbon disk, counter: glassy carbon disk, reference: silver wire) and electrolyte (200 $\mathrm{mM}$ of salt dissolved in EtOH). The scan rate for the Tafel study was $0.5 \mathrm{mV} / \mathrm{s}$ with vigorous stirring.

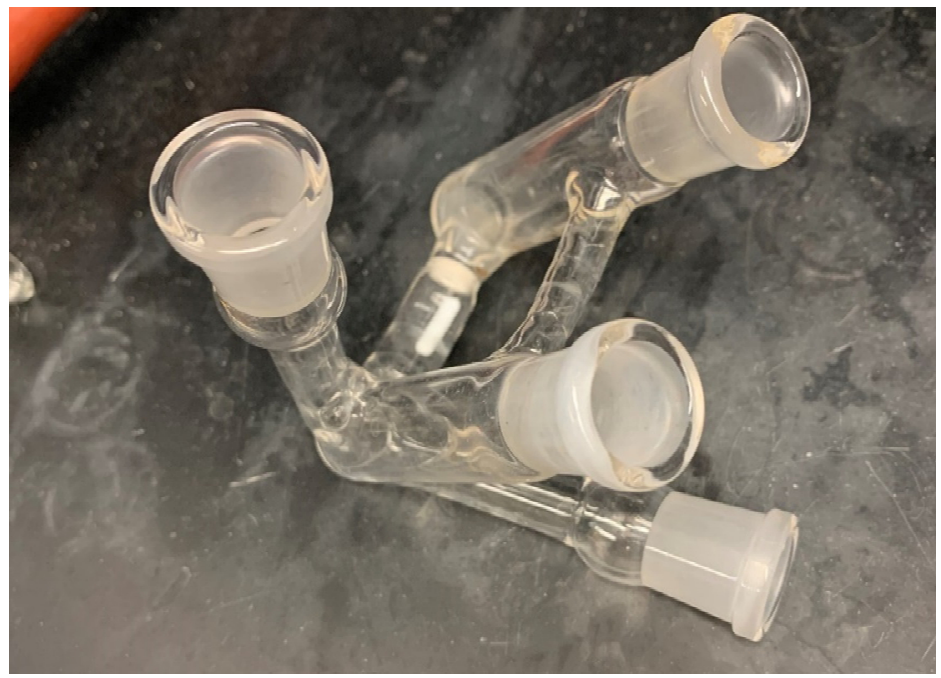

Glass 2-compartment cell used for electrochemical experiments. The compartments are separated by a glass frit. 


\section{Product Identification and Quantification}

The DEE product was characterized by GC-MS analysis (Shimadzu QP-2010) and quantitative ${ }^{1} \mathrm{H}-\mathrm{NMR}$ spectroscopy (Varian Vnmrs $700 \mathrm{MHz}$ ). The GC-MS sample was prepared by diluting the post-electrolysis aliquot in 200 proof ethanol. The quantitative ${ }^{1} \mathrm{H}-\mathrm{NMR}$ sample was prepared by diluting the post-electrolysis aliquot in deuterated chloroform. NMR signals from the $\mathrm{Bu}_{4} \mathrm{NCl}$ electrolyte are applied as the internal standard for quantification.

The FT-IR measurement was carried out on a Thermo-Nicolet IS-50 spectrometer with its ATR accessory. During measurement, the background is set to ambient air, and the aliquot was dropped on the ruby directly without dilution. For the control experiment against the CPC sample, a same electrochemical cell was assembled and left stirring for the same time, but with no charge passed.

The UV-vis absorption measurement was carried out on an Agilent Cary 5000 UV-Vis-NIR spectrophotometer with a zero-baseline calibration, of which zero corresponds to air and baseline corresponds to the unaltered mother solution of EtOH with $200 \mathrm{mM} \mathrm{Bu}_{4} \mathrm{NCl}$ dissolved. Before the measurement, the aliquot underwent dilution by the mother solution to avoid exceeding the signal upper limit.

Chloride recovery was carried out by adding excess silver nitrate $\left(\mathrm{AgNO}_{3}\right)$ aqueous solution to precipitate $\mathrm{AgCl}\left(\mathrm{K}_{\mathrm{sp}}=1.8 \times 10^{-10}\right.$ at $\left.25^{\circ} \mathrm{C}\right)$. The precipitate was subsequently washed with water, $\mathrm{EtOH}$, and water before being dried in a vacuum oven at $60^{\circ} \mathrm{C}$. Then, the leftover powder was collected and weighed to calculate the chloride ion concentration in the mother liquor.

EtOCl titration with $\mathrm{NH}_{4} \mathrm{I}$ is carried out with a slight change to a reported method. ${ }^{1}$ First, $5 \mathrm{~mL}$ of electrolyte was added to an aqueous solution with excess KI, which was acidified by acetic acid. Stoichiometrically, the EtOCl will oxidize iodide in solution to iodine rapidly. Subsequently, the iodine was titrated by L-ascorbic acid, which can be quantified. The corresponding chemical reactions are listed below.

$$
\begin{aligned}
& \mathrm{EtOCl}+2 \mathrm{I}^{-}+\mathrm{H}^{+} \rightarrow \mathrm{EtOH}+\mathrm{Cl}^{-}+\mathrm{I}_{2} \\
& \mathrm{I}_{2}+\mathrm{C}_{6} \mathrm{H}_{8} \mathrm{O}_{6} \rightarrow \mathrm{C}_{6} \mathrm{H}_{6} \mathrm{O}_{6}+2 \mathrm{I}^{-}+2 \mathrm{H}^{+}
\end{aligned}
$$

Attempts were made to observe the acetaldehyde intermediate by low-temperature ${ }^{1} \mathrm{H}-\mathrm{NMR}$ spectroscopy. Briefly, after $1 \mathrm{~h}$ CPC experiment, an aliquot was immediately diluted in $\mathrm{CDCl}_{3}$ and then instantly cooled down by liquid $\mathrm{N}_{2}$. The sample was inserted to the NMR instrument which was pre-cooled down to $-80{ }^{\circ} \mathrm{C}$. However, even at low temperature, the spectrum obtained showed no presence of acetaldehyde, while the formation of DEE was observed.

${ }^{1}$ Chattaway, F. D.; Backeberg, O. G. CCCLVI.-Alkyl hypochlorites. J. Chem. Soc., Trans. 1923, 123, 2999-3003. 


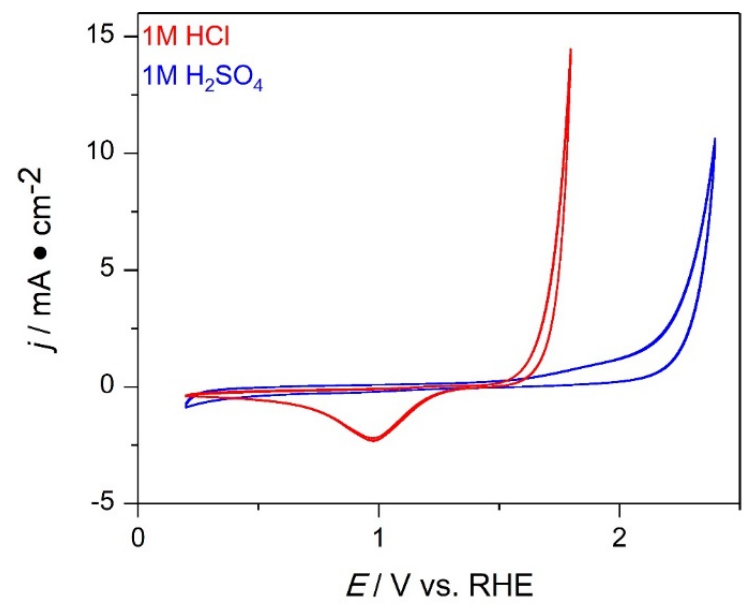

Figure S1. CV traces in aqueous solutions containing acid electrolytes at a scan rate of 100 $\mathrm{mV} / \mathrm{s}$. Working electrode: glassy carbon disk; reference electrode: $\mathrm{Ag} / \mathrm{AgCl}$. Redo_200TBACI_Working_CDCl3_nostd Redo_200TBACI
Proton Spectrum
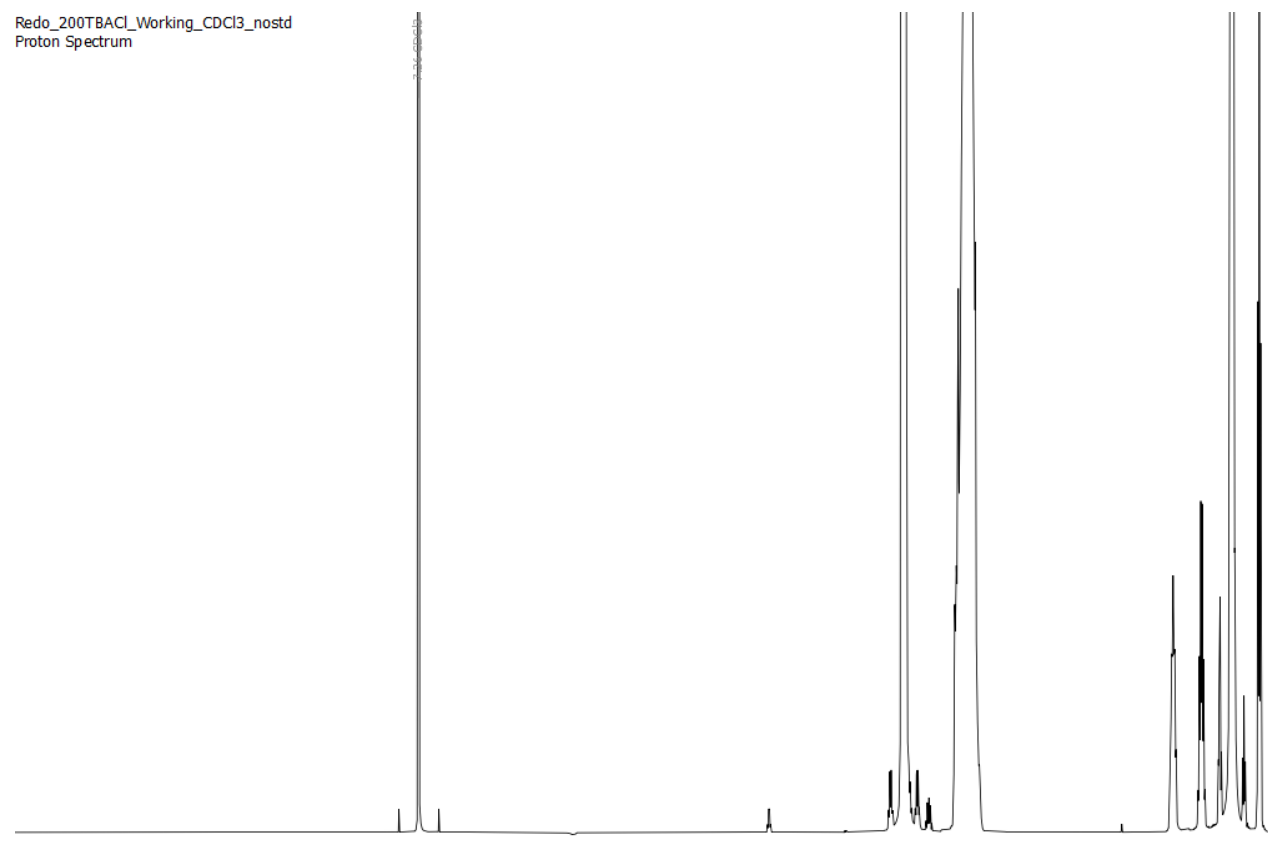

$10.0 \quad 9.5$ $\begin{array}{lllllllll}9.0 & 8.5 & 8.0 & 7.5 & 7.0 & 6.5 & 6.0 & 5.5 & 5.0 \\ \mathrm{f} 1(\mathrm{ppm})\end{array}$

Figure S2. General ${ }^{1} \mathrm{H}-\mathrm{NMR}$ spectrum of the reaction mixture after $\mathrm{CPC}$ experiments. Chemical shifts: chloroform $(7.26,1 \mathrm{H})$. tetrabutylammonium chloride $(3.21,8 \mathrm{H}, \mathrm{m} ; 1.58,8 \mathrm{H}$, $\mathrm{m} ; 1.37,8 \mathrm{H}, \mathrm{m} ; 0.94,12 \mathrm{H}, \mathrm{t})$. EtOH $(3.60,2 \mathrm{H}, \mathrm{q} ; 3.15,1 \mathrm{H} ; 1.14,3 \mathrm{H}, \mathrm{t})$. DEE $(4.61,1 \mathrm{H}, \mathrm{q}$; $3.43,4 \mathrm{H}, \mathrm{m}$; other peaks overlay with the solvent peak). 

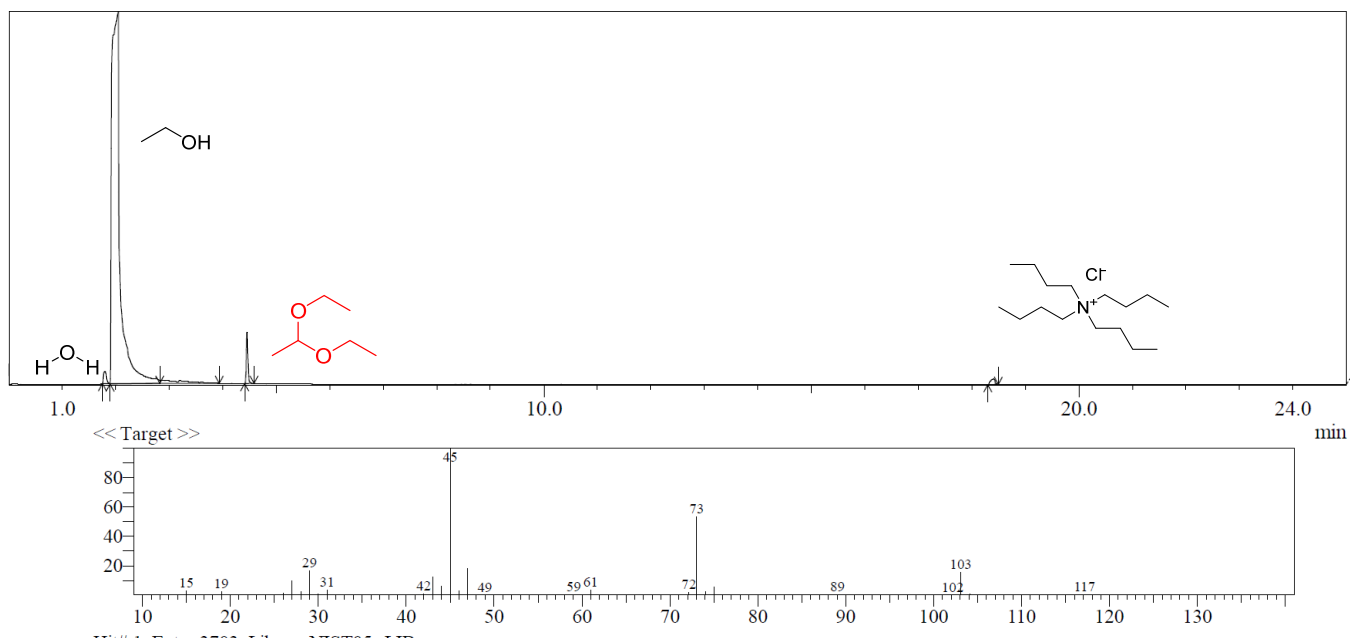

Hit\#:1 Entry:3703 Library:NIST05s.LIB

SI:97 Formula:C6H14O2 CAS:105-57-7 MolWeight:118 RetIndex:705

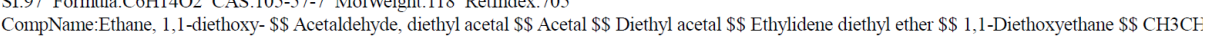

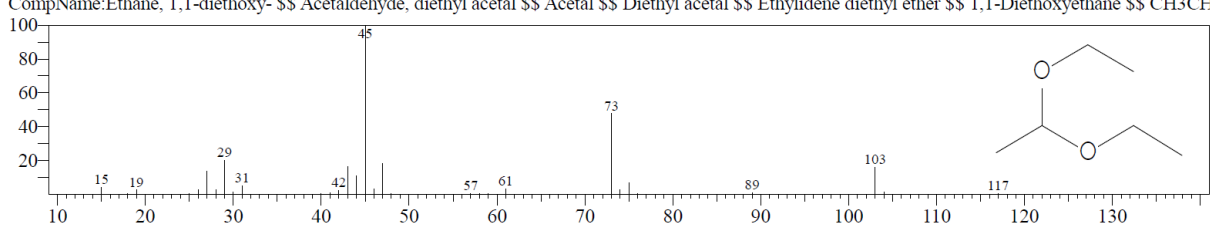

Figure S3. GC-MS trace of the post CPC aliquot with $\mathrm{m} / \mathrm{z}$ ratio graph of the DEE peak (retention time $=4.45 \mathrm{~min}$ ) against the standard graph.

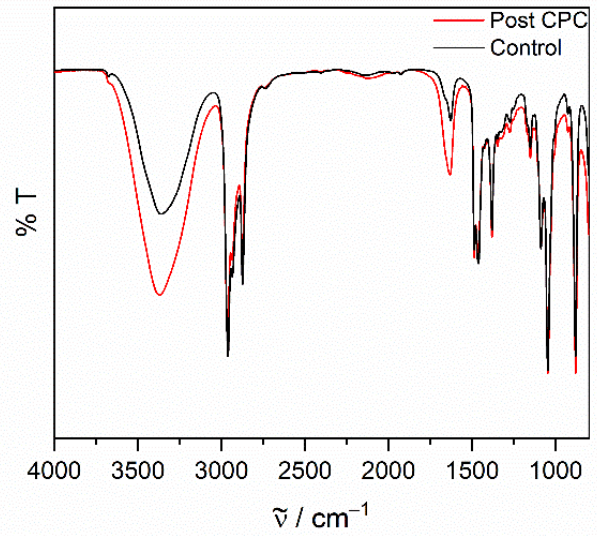

Figure S4. FT-IR spectrum of an aliquot of the reaction mixture recorded before (black) and after (red) the CPC experiment. The \% transmittance value was normalized, and the only differences are attributed to water (the reaction byproduct): $v_{\mathrm{O}-\mathrm{H}}\left(3360 \mathrm{~cm}^{-1}\right)$ and $\delta_{\mathrm{H}-\mathrm{O}-\mathrm{H}}(1630$ $\left.\mathrm{cm}^{-1}\right)^{2}$

${ }^{2}$ Mojet, B. L.; Ebbesen, S. D.; Lefferts, L. Light at the interface: the potential of attenuated total reflection infrared spectroscopy for understanding heterogeneous catalysis in water. Chem. Soc. Rev. 2010, 39(12), 4643-4655. 


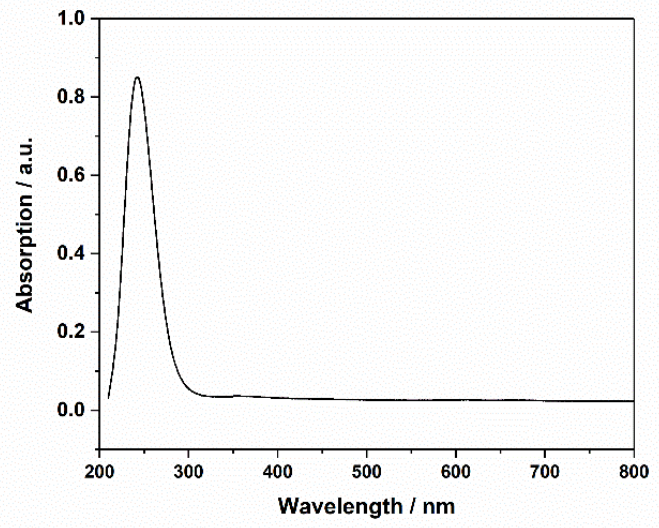

Figure S5. Extended-range UV-vis spectrum of a diluted aliquot after the $1 \mathrm{~h}$ CPC experiment. The EtOCl signature peak remains as the only notable absorption feature throughout the UVvis range.

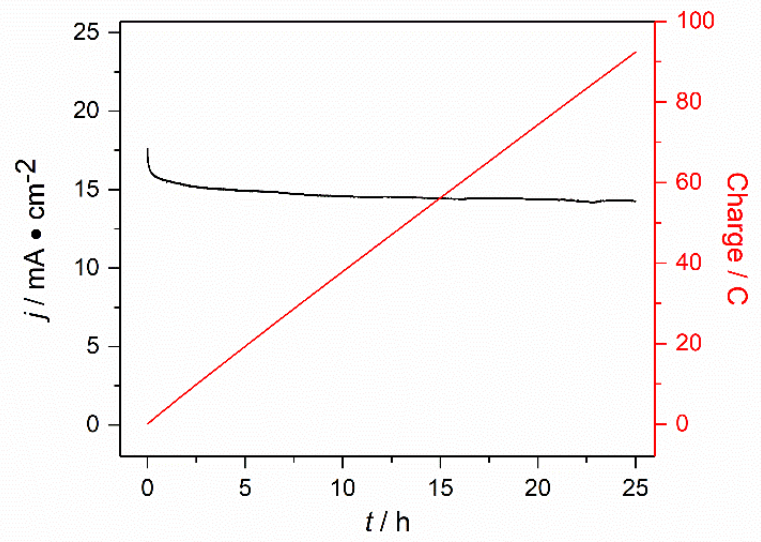

Figure S6. Long-time CPC experiment for measuring chloride recovery. CPC potential: +1.61 $\mathrm{V}$ vs. $\mathrm{Fc}^{+/ 0}$. Black: CPC $i-t$ curve. Red: Charge passed $q-t$ from integrating the $i-t$ curve. In total, $96.77 \mathrm{C}$ of charge passed, which would correspond to $50.1 \%$ of chloride being consumed (100.3 mM chloride consumption out of $200 \mathrm{mM}$ ) if chloride reacted stoichiometrically. 


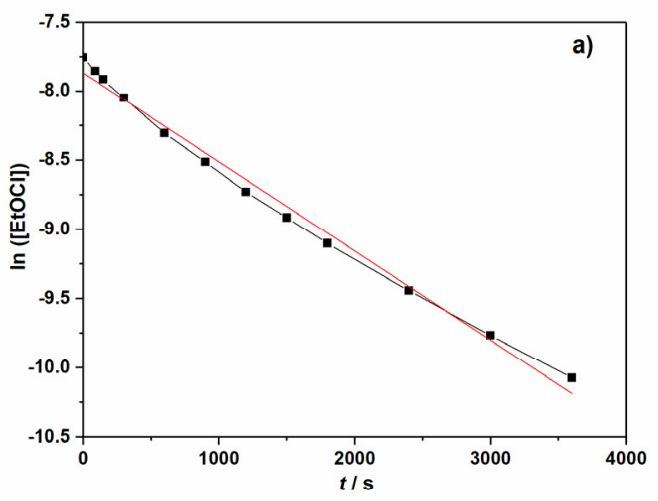

Trial a): slope $=-6.436 \cdot 10^{-4} \mathrm{~s}^{-1}$

Trial b): slope $=-6.636 \cdot 10^{-4} \mathrm{~s}^{-1}$

Trial c): slope $=-7.616 \cdot 10^{-4} \mathrm{~s}^{-1}$

$k=6.896 \pm 0.516 \cdot 10^{-4} \mathrm{~s}^{-1}$
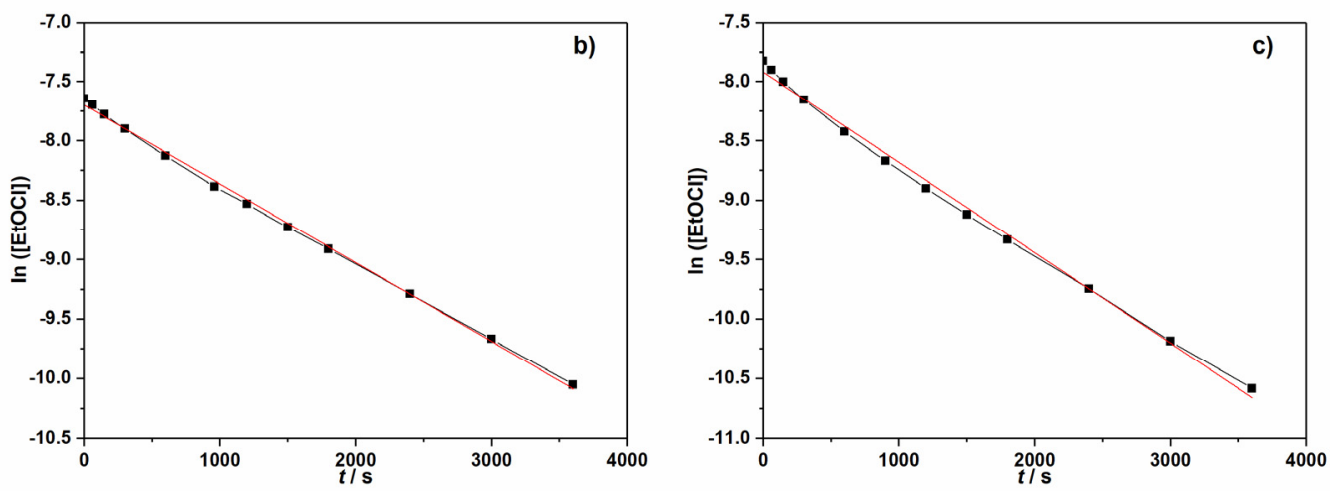

Figure S7. Replicates of EtOCl degradation kinetics presented in Figure 3. The concentrations were determined by a combination of UV-vis spectroscopy and a titration experiment.

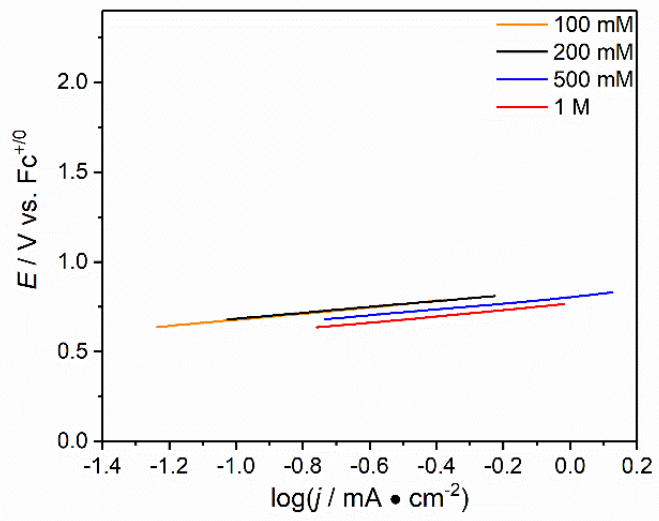

Figure S8. Tafel slopes for varying concentration of chloride electrolyte in ethanol solution. The slopes are provided in the Table below.

\begin{tabular}{cc}
\hline$\left[\mathrm{Bu}_{4} \mathrm{NCl}\right] / \mathrm{mM}$ & Tafel slope $/ \mathrm{mV} \cdot \mathrm{dec}^{-1}$ \\
\hline 100 & 173.7 \\
200 & 162.7 \\
500 & 169.4 \\
1000 & 176.0 \\
\hline
\end{tabular}

